\title{
Experimental and numerical characterisation of heat flow during flame cutting of thick steel plates
}

\author{
Raphaël Thiébaud ${ }^{\mathrm{a}}$, Jean-Marie Drezet ${ }^{\mathrm{b}, *}$, Jean-Paul Lebet ${ }^{\mathrm{a}}$ \\ a Steel Structures Laboratory (ICOM), Ecole Polytechnique Fédérale de Lausanne, Civil and Environmental Engineering (ENAC), EPFL - ENAC - ICOM, Station \\ 18, CH-1015 Lausanne, Switzerland \\ ${ }^{\mathrm{b}}$ Computational Materials Laboratory (LSMX), Ecole Polytechnique Fédérale de Lausanne, School of Engineering (STI), EPFL - STI - IMX - LSMX, Station 12, \\ $\mathrm{CH}-1015$ Lausanne, Switzerland
}

\section{A R T I C L E I N F O}

\section{Article history:}

Received 6 April 2013

Received in revised form

10 September 2013

Accepted 13 September 2013

Available online 23 September 2013

\section{Keywords:}

Flame cutting

Heat flow

Heat affected zone

\begin{abstract}
A B S T R A C T
Temperatures measurements during flame cutting of a thick steel plate and measurements of the extension of the fusion and heat affected zones and Vickers hardness after cutting have been performed. Additionally, a 3-D thermal model for simulation of flame-cutting has been developed. For the sake of simplicity, the model depends only on two parameters: (i) the heat density within the flame, and (ii) the heat transfer coefficient within the air gap that forms behind the cut. The results show that the model is able to properly reproduce the measured temperature curves and the heat affected zone with an input power in the same range of those reported in the literature. A process efficiency of $26.5 \%$ is found in the steady state regime of flame-cutting.
\end{abstract}

(C) 2013 Elsevier B.V. All rights reserved.

\section{Introduction}

Flame-cutting is a thermal cutting process that is largely used in steel construction. It allows cutting of thin plates from $3 \mathrm{~mm}$ to much thicker plates up to $150 \mathrm{~mm}$ in thickness (McQuade, 2010). This technology uses gases, usually propane and oxygen, to produce a controlled flame that is able to melt down the steel thus forming a cut. To our knowledge, very few studies on the characterisation of heat flow within the steel during flame cutting are reported in literature.

The principle of flame-cutting is based on a chemical reaction of oxygen with the base metal at elevated temperatures. More precisely, the material is heated locally via a flame obtained from the combustion of a specific fuel gas mixed with oxygen. The metal is melted by a jet of pure oxygen creating a continuous chemical reaction between the oxygen and the metal. The iron oxide that forms is blown away by the jet of oxygen thus creating a cut in the piece and a heat affected zone (HAZ) adjacent to the cut.

In the 1940s, Rosenthal proposed a mathematical approach for the heat distribution during welding and cutting (Rosenthal, 1941) by using a combination of heat point sources. To find analytical

\footnotetext{
* Corresponding author at: EPFL - STI - IMX - LSMX, Station 12, CH-1015 Lausanne, Switzerland. Tel.: +41 216933920.

E-mail addresses: raphael.thiebaud@epfl.ch (R. Thiébaud), jean-marie.drezet@epfl.ch (J.-M. Drezet), jean-paul.lebet@epfl.ch (J.-P. Lebet).
}

solutions, thermophysical properties were assumed to be constant, the medium was considered as semi-infinite and latent heat effects were ignored. Concerning flame cutting per se, the oxyfuel gas cutting process was studied by Adedayo (Adedayo, 2011) who reported different chemical reactions taking place in the flame and MuñozEscalona et al. (2006) investigated the influence of different type of gases and their process on cut quality of steel plates; both studies did not mention any heat associated with these reactions. Terasaki et al. (2009) experimentally investigated the heat input and the distribution of heat generated by gas cutting. They proposed a model of heat input that take into account the preheating flame, the oxidation reaction and dross but no thermal heat flow analysis has be performed. Osawa et al. (2012) studied the transient heat transfer during oxyfuel gas piercing by using genetic algorithms. They determined the heat input by comparing the measured and calculated plate back face temperatures during spot heating tests and found out heat power for $6 \mathrm{~mm}$ steel plates between 7 and $9.25 \mathrm{~kW}$ depending on the gas mixture used for piercing. Their approach is interesting but as it has to do with a transient thermal field, many parameters have to be tuned at the same time. Laserassisted oxygen cutting was studied by O'Neill and Gabzdyl (O'Neill and Gabzdyl, 2000) who reported input (exothermic) powers ranging from 13 to $23 \mathrm{~kW}$ depending on plate thickness and cutting speed. Finally, Ermolaev et al. (Ermolaev, 2013) carried out a theoretical and experimental study for hybrid laser-assisted oxygen cutting of mild steel sheets but did not report specifically heat input powers. 
(a)

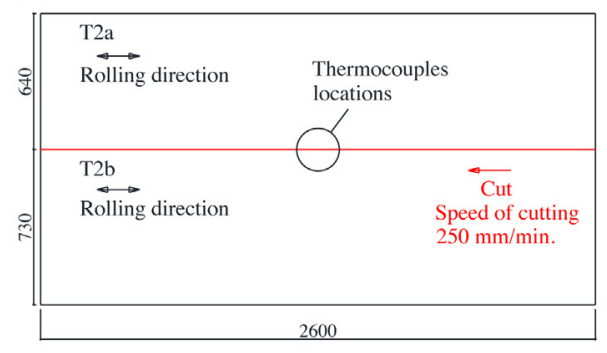

(b)

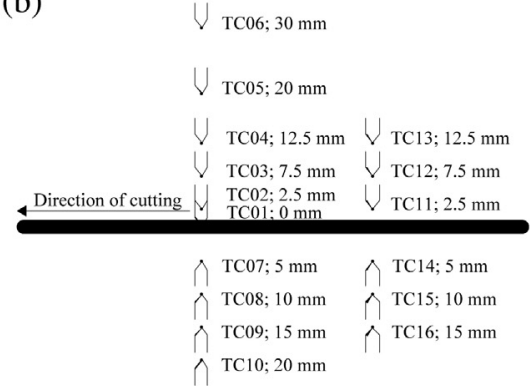

Fig. 1. Design of the temperature measurements during flame cutting, (a) top view of the measurements, dimensions in mm, (b) thermocouples (TC) locations.

Among the very few studies addressing the steady state heat flow in steel flame cutting, the work of Lindgren et al. (1983) is the first one to combine a computational approach with measurements for $50 \mathrm{~mm}$ thick plates cut at $4.83 \mathrm{~mm} / \mathrm{s}$. The authors modeled the heat flow during flame cutting within a 2D section transverse to the direction of cutting using finite elements. They studied the influence of preheating the plate prior to cutting and calibrated the heat input with the help of the extension of the heat affected zone. They reported lower residual stresses in the preheated plate thus preventing subsequent cracking.

This present study is based on an experimental and three dimensions numerical study aimed at determining the steady state heat flow that develops during flame cutting in thick steel plates. First, temperature measurements are presented together with an estimation of the heat affected zone. Second, a thermal model based on the finite element method is presented that takes into account the heat input within the flame and the heat loss associated with the leakage of the melted material. Finally, results are presented and the parameters of the heat flow model are calibrated against both temperature measurements and heat affected zone. This result forms the first step of a thermo-mechanical analysis as explain by Lindgren (2001) which allow assessing the residual stresses created by flame-cutting. Those residual stresses could be calibrated with experimental residual stress measurements (Thiébaud and Lebet, 2012) in order to define a model for thick flame-cut plates and welded plates used in bridge I-girder construction. Such model could serve as input information to contribute to study fatigue and stability issues of such girders.

\section{Experimental}

\subsection{Material and process}

The manufacturing of steel bridge girders is usually made in two steps. First, steel flanges, which constitute the girders, are flamecut from rolled plates. Second, these pieces are assembled usually by submerged arc welding method (SAW). Both steps introduce residual stresses which modify significantly the internal stresses present in the plates after rolling. The flame-cutting process used to fabricate the specimens and the temperature measurements are fully detailed in Thiébaud and Lebet (Thiébaud and Lebet, 2012) and are briefly presented hereafter.

A fine grain structural steel S355 N, according to EN 10025-3 (2004), is chosen for the study as it is commonly used in bridge construction. A rolled plate, $60 \mathrm{~mm}$ in thickness, $1370 \mathrm{~mm}$ in width and $2600 \mathrm{~mm}$ in length is flame cut to obtain two flanges as shown in Fig. 1a. The direction of cutting is parallel to the rolling direction and cutting is performed by an oxypropane process with a speed of $250 \mathrm{~mm} / \mathrm{min}$. The cutting speed depends mainly on the type of steel and the plate thickness and is tuned by the machine manufacturer in order to obtain a good surface quality as explain in Muñoz-Escalona et al. (2006).

\subsection{Temperature measurements}

Prior to flame cutting, the plate is instrumented with two rows of type $\mathrm{K}$ thermocouples located on the upper side and lower side of the plate as reported in Fig. 1b. The first row is located $1300 \mathrm{~mm}$ from the edge and consists of six sensors. Similarly, the second row consists of ten thermocouples situated $100 \mathrm{~mm}$ from the edge. These thermocouples are spot welded onto the steel plate at different distances from the torch path. Positioning of the various thermocouples is designed to provide redundancy in the thermal measurements, as the measurements only depend on the distance from the torch path and not on the position along the torch path. This is the case for thermocouples located in both rows at $2.5 \mathrm{~mm}$, $7.5 \mathrm{~mm}$ and $12.5 \mathrm{~mm}$ on the upper face. Thus the thermal histories recorded during flame cutting are characteristic of the steady state regime of the process. The frequency of thermal readings is set to $5 \mathrm{~Hz}$ as fast heating and cooling are expected, especially close to the torch path.

Fig. 2 shows the raw temperature measurements which exhibit two peaks as the torch travels from the first to the second row of thermocouples. Temperature increase rapidly when the torch passes near the thermocouple and the maximum temperature increases when the distance to the torch path decreases. Note that the highest temperature is around $1550^{\circ} \mathrm{C}$ and corresponds to the measurement capacity of type $\mathrm{K}$ thermocouples.

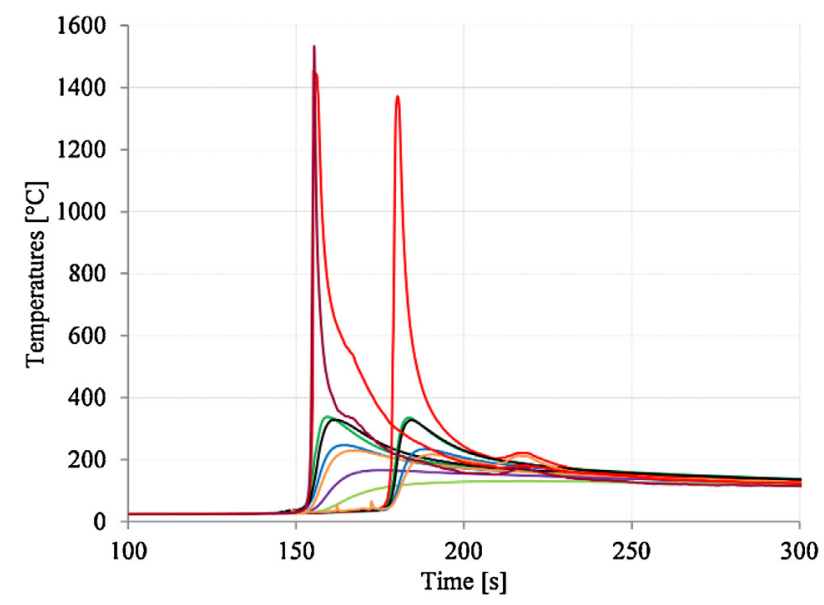

Fig. 2. Experimental results: raw temperatures histories, identical colors are used for thermocouples located at the same distance to the torch path. 


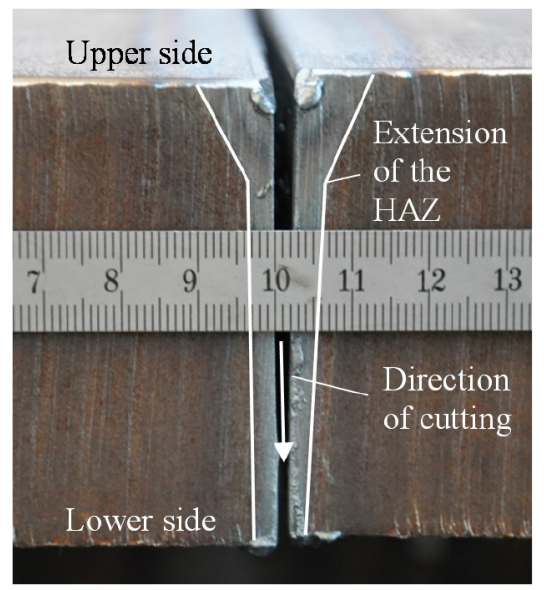

(a)

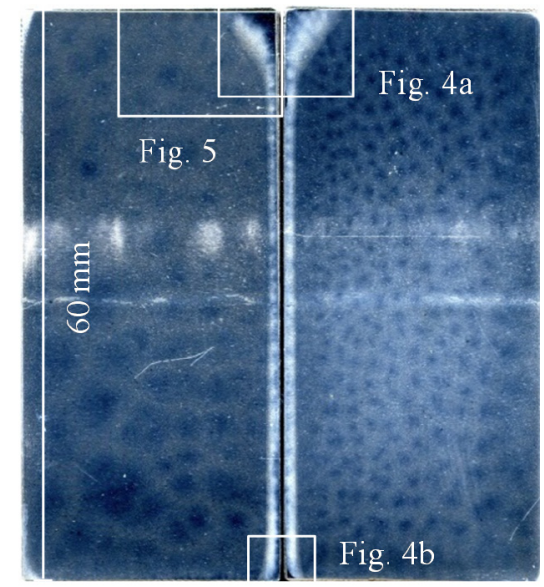

(b)

Fig. 3. Experimental results, (a) side-view of the flame-cut specimen, (b) scanning of the HAZ.

In the $1550^{\circ} \mathrm{C}$ case, the signals become erratic upon cooling as the thermo elements might have been damaged. The repeatability of the measurements is highlighted by the use of similar colors in Fig. 2 for thermocouples located at the same distance to the torch path. As these temperature measurements are performed in the middle of the plate, a thermal steady state is reached and temperature histories can be transformed into temperature profiles in a frame attached to the torch using the cutting speed. These profiles are used later to calibrate the missing input parameters of the heat flow model presented in Section 3.

\subsection{Study of the heat affected zone (HAZ)}

The extension of both the fusion zone and the heat affected zone can be assessed and measured by the change in base material color on both sides of the cut as illustrated in Fig. 3. The full width of the fusion zone is admitted to be the same as the width of cutting groove. The average value of the groove measure $2 \mathrm{~mm}$ (Fig. 3a) with the present process conditions. This width will be used in the modeling of the thermal field in section 3.

The metallography study of the HAZ was done on specimen located in the center of the steel plate where HAZ was uniform. In order to obtain a visible HAZ pattern, first, the surface has been adequately prepared by polishing, and second, the polished surface has been attacked by a $5 \%$ Nital solution. Fig. 3 b reveals the shape of HAZ by the change in base material color on both sides of the cut. The general shape provided by Fig. 3b shows three mains parts of the HAZ due to flame-cutting process. On the upper side, i.e. the face hit by the heating flame, the shape is open due to the flame action which heat more the material near the surface. The enlargement (Fig. 4a) shows that the maximum (resp. minimum) width of the "cone" formed by the HAZ measures $7.5 \mathrm{~mm}$ (resp. $1.8 \mathrm{~mm}$ ) and the slope (angle) is close to $45^{\circ}$. In the thickness where oxidation reaction governs, the shape is parallel to the cut with a width of less than $1.9 \mathrm{~mm}$ (Fig. 4). On the lower side (Fig. 4b), the shape appears slightly open due to the heat conducted from dross which are visible in Fig. 3a.

Vickers hardness tests results of the upper part of the HAZ are plotted on Fig. 5. Contour lines confirm the shape of "cone" revealed by Figs. 3 and 4. It can be observed that higher Vickers hardness values are located close to the cut and decrease with the thickness and the distance to the cut. In Fig. 5, the value of Vickers hardness varies between $150 \mathrm{HV}$ for the base material to $450 \mathrm{HV}$ for the cut edge where phase transformation is expected.

\subsection{Heat flow modeling}

The present section is dedicated to the finite element calculations. The flame cutting heat flow model is created in CalcoSoft (CalcoSoft, 2005). A transport term is included in the heat equation and the steady state solution is sought assuming proper boundary conditions and heat input. Only two parameters, determined using the experimental results presented in Section 2, are considered in the model.

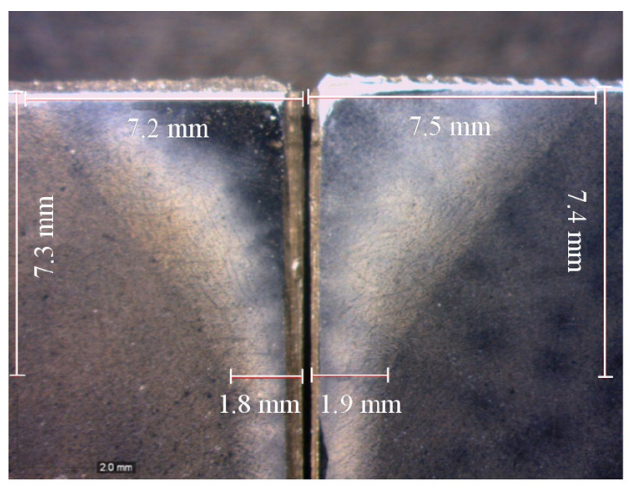

(a)

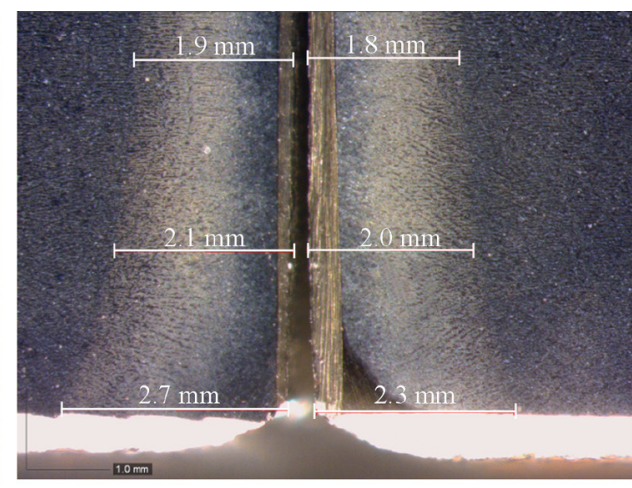

(b)

Fig. 4. Binocular enlargement, (a) upper side, (b) lower side. 


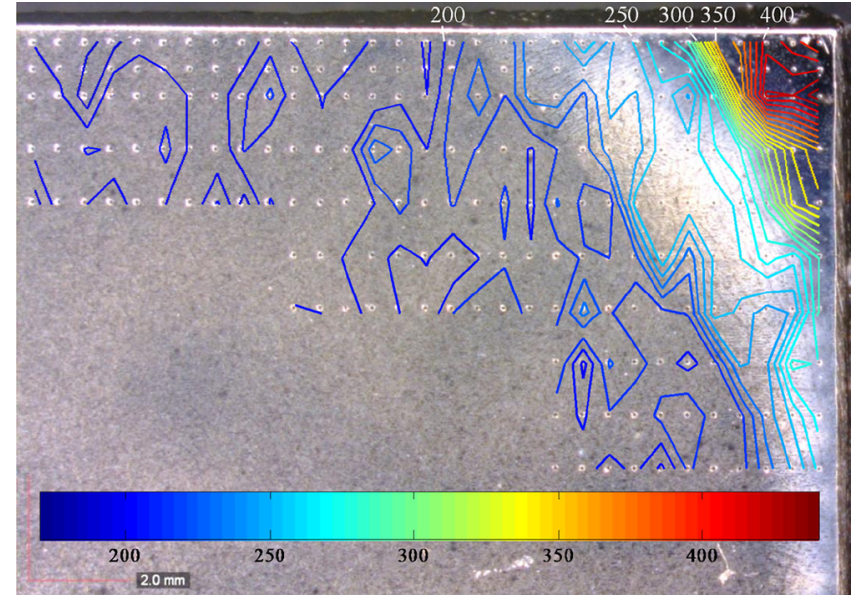

Fig. 5. Vickers hardness test results represented by contour lines, unit in HV.

\subsection{Geometry and finite element mesh}

Using symmetry, only half of a steel plate is modeled. The dimensions are: $300 \mathrm{~mm}$ in length ( $x$ direction), $60 \mathrm{~mm}$ in thickness $(z$ direction), and $30 \mathrm{~mm}$ in width ( $y$ direction), as shown in Fig. 6. The flame is located at $x=49 \mathrm{~mm}$ where the mesh is refined due to the expected high thermal gradients around the heat source. The mesh consists of 418,000 elements and 77,000 nodes. Behind the position of the torch, an empty space $1 \mathrm{~mm}$ in width is present to model an air gap between the two flanges.

\subsection{Governing equations}

Adopting an eulerian approach, a transport term is included in the heat flow equation which is formulated using an enthalpy formulation to take into account the latent heat associated with fusion and solidification:

$$
\frac{\partial H}{\partial t}+v \nabla H=\operatorname{div}(k \nabla T)+Q \text { with } H=\int_{0}^{T} C p d T+L(1-f s)
$$

In Eq. (1), $H$ is the volumetric enthalpy, $C p$ is the volumetric heat capacity of the material, $T$ is the temperature, $k$ is the thermal conductivity and $v$ is the speed of the torch (set to $250 \mathrm{~mm} / \mathrm{min}$ ). $Q$ corresponds to the heat input associated with the different chemical reactions that occur within the flame. $L$ is the volumetric latent heat, $1.9410^{9} \mathrm{~J} / \mathrm{m}^{3}$, and $f s$ is the volume fraction of solid that is assumed to vary linearly between the solidus temperature, $1465^{\circ} \mathrm{C}$, and the liquidus temperature, $1544{ }^{\circ} \mathrm{C}$, of the $\mathrm{S} 355 \mathrm{~N}$ steel. Once the temperature field has reached steady state, the heat transport must balance the heat dissipated by diffusion and the heat input.

\subsection{Thermophysical properties}

The thermal conductivity, specific heat capacity and density of the $\mathrm{S} 355 \mathrm{~N}$ steel are presented in Fig. 7. Notice that the thermal

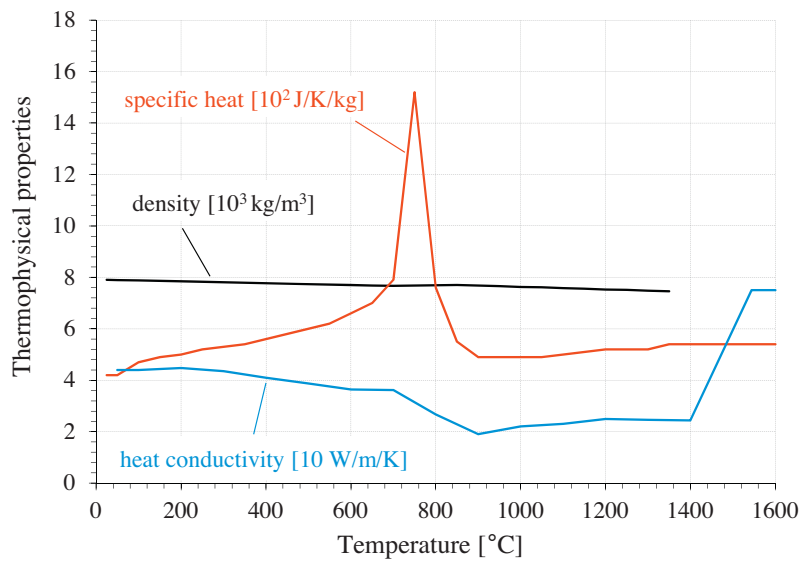

Fig. 7. Temperature dependency of the material properties from Mertens (2012).

conductivity is multiplied by a factor of three in the liquid state to simulate high heat convection.

\subsection{Definition of the heat source}

The heat input generated by the different exothermal chemical reactions taking place in the flame during cutting is assumed to be uniformly distributed within a cylinder located around the flame with a radius, $R$, equal to the half thickness of the groove, i.e. $1 \mathrm{~mm}$. With the help of a user routine, the heat input is defined as:

for $\left(\left(x-x_{0}\right)^{2}+y^{2}\right) \leq R^{2}, Q=Q_{\text {in }}$

where $x_{0}=49 \mathrm{~mm}$ is the position of the flame and $R=1 \mathrm{~mm}$. Near the top face of the plate, $R$ increases linearly from $1 \mathrm{~mm}$ to $2 \mathrm{~mm}$ over a distance of $2 \mathrm{~mm}$ in order to reproduce the upper shape of the cut presented in Figs. 3 and 4 . The parameter $Q_{\text {in }}$ is to be calibrated using the temperature measurements presented in Section 2.

\subsection{Boundary conditions}

On the top $(z=60 \mathrm{~mm})$ and bottom sides $(z=0 \mathrm{~mm})$ of the domain, a heat transfer coefficient equal to $20 \mathrm{~W} / \mathrm{m}^{2} \mathrm{~K}$ is applied together with an ambient temperature of $27.5^{\circ} \mathrm{C}$. An adiabatic condition is applied on the symmetry plane $y=0$ whereas a heat transfer coefficient, $h_{\text {gap }}$, is used to model possible heat loss within the gap. The mean temperature in the gap is assumed to be around $200^{\circ} \mathrm{C}$. The value of $h_{\text {gap }}$ is not known a priori and requires a calibration such as $Q_{i n}$. A constant temperature of $27.5^{\circ} \mathrm{C}$ is applied throughout the face $x=0$ and a temperature of $200^{\circ} \mathrm{C}$ is applied on the face $x=300 \mathrm{~mm}$. The temperature profile measured $30 \mathrm{~mm}$ from the torch path (cf. Fig. 2) is imposed as a Dirichlet boundary condition at the face $y=30 \mathrm{~mm}$. The heat loss associated with the leakage of hot metal is modeled by a heat flux applied on the lower surface of the cylinder used to define the heat input. During an increment of time, dt, the heat loss is $v d t R H\left(\bar{C}_{p} T+L\right)$ where $\bar{C}_{p}$ is the mean volumetric heat capacity, $4.10^{6} \mathrm{~J} / \mathrm{m}^{3} \mathrm{~K}$ and $\mathrm{h}$ is the plate

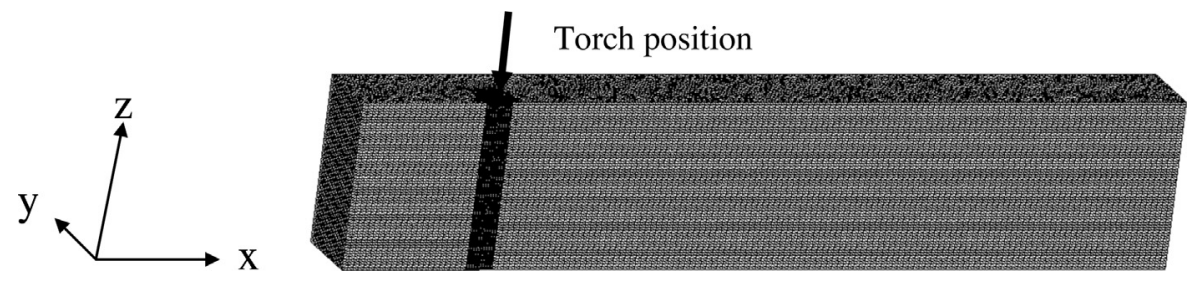

Fig. 6. Mesh of the computation domain and position of the torch. 
thickness, $60 \mathrm{~mm}$. When divided by half the section of the cylinder, this heat loss corresponds to a heat flux defined as follows:

for $\left(\left(x-x_{0}\right)^{2}+y^{2}\right) \leq R^{2}$ and $z=0, Q_{\text {out }}=-\frac{2 v h}{\pi R}\left(\bar{C}_{p} T+L\right)$

This heat flux is fully determined and does not need any calibration. With a temperature of $2000{ }^{\circ} \mathrm{C}$, the leakage of hot material corresponds to a heat loss of $2.5 \mathrm{~kW}$ for the present model and of $5 \mathrm{~kW}$ for the whole process; the factor 2 comes from the fact that only half of the plate is considered in the computation domain.

\section{Results}

\subsection{Calibration of heat flow parameters}

Two parameters $Q_{\text {in }}$ and $h_{\text {gap }}$ require a calibration. To do so, the thermal histories presented in Fig. 2 are transformed into thermal profiles using the torch velocity and both parameters are varied until the measured profiles, calculated profiles, and HAZ extension match. This kind of inverse method (Rappaz et al., 1995) is eased in the present case as $Q_{\text {in }}$ dictates the maximum temperatures of each profile whereas $h_{\text {gap }}$ influences the cooling rate for each profile. Fig. 8 shows the agreement that was obtained with $Q_{\text {in }}=1.0 \mathrm{e}^{11} \mathrm{~W} / \mathrm{m}^{3}$ and $h_{\text {gap }}=500 \mathrm{~W} / \mathrm{m}^{2} \mathrm{~K}$ for the profiles located at 10,15 and $20 \mathrm{~mm}$ from the torch path. Profiles closer to the torch were discarded causing erratic signals and uncertain thermocouple locations. Fig. 9 shows that the HAZ is also well reproduced by the present model.

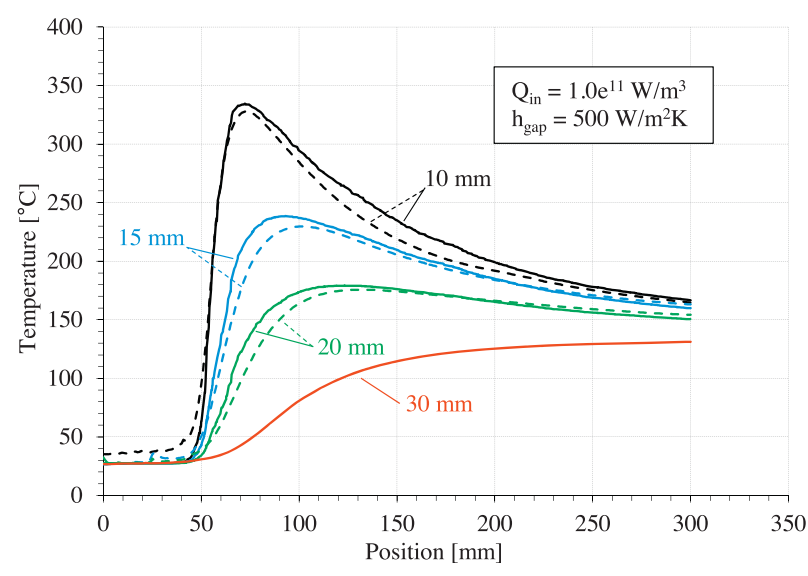

Fig. 8. Measured (dashed lines) and calculated (continuous lines) temperature profiles after model calibration.

\subsection{Heat flow during flame cutting}

Once the two parameters $Q_{\text {in }}$ and $h_{\text {gap }}$ are calibrated, the present heat flow model yields many results such as local thermal gradients, heating and cooling curves as a function of the distance to the torch path and extension of the fusion zone. Such results are presented in Figs. 10-12. The models are useful to predict the solid state phase transformations that occur in the steel adjacent to the cut and the thermally induced stress generation within the flanges. Thermally

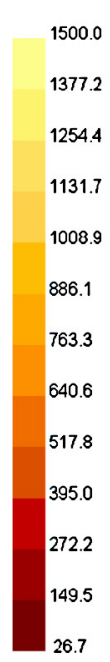

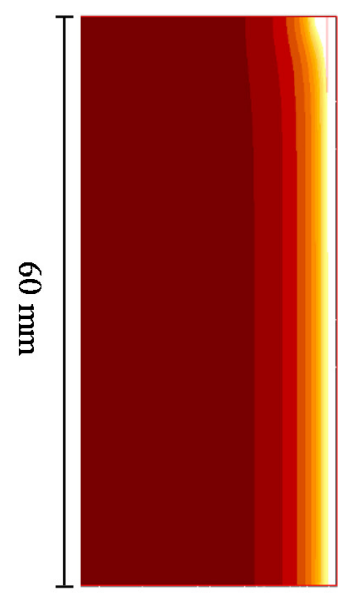

(a)

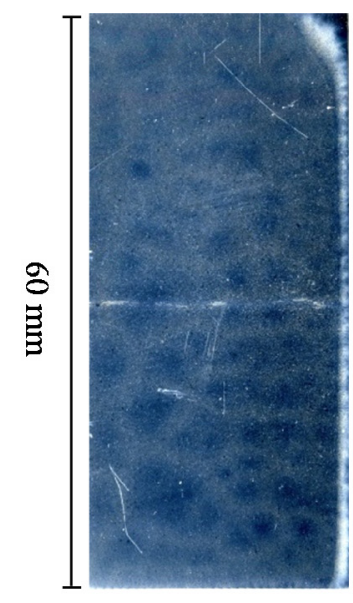

(b)

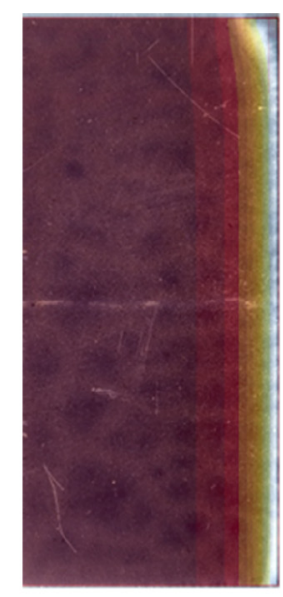

(c)

Fig. 9. (a) Calculated and (b) scanned HAZ, (c) superposition of (a) and (b) after model calibration.

$$
\begin{aligned}
& 1500.0 \\
& 1377.2 \\
& 1254.4 \\
& 1131.7 \\
& 1008.9 \\
& 886.1 \\
& 763.3 \\
& 640.6 \\
& 517.8 \\
& 395.0 \\
& 272.2 \\
& 149.5 \\
& 26.7
\end{aligned}
$$

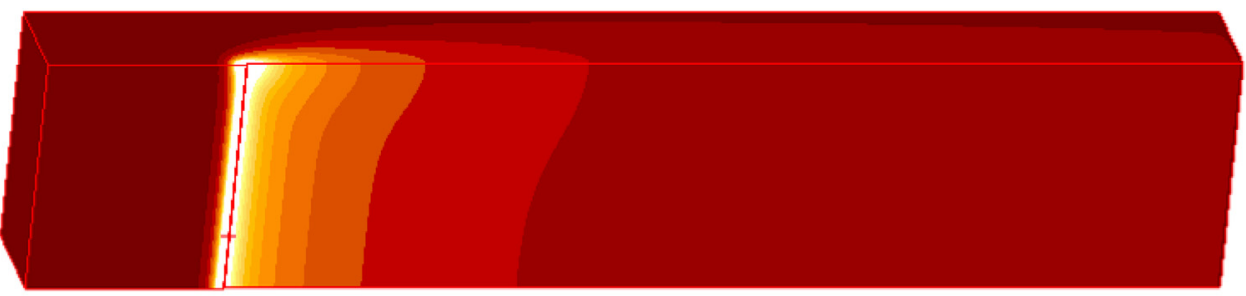

Fig. 10. Steady state temperature distribution (temperatures lower than $1500^{\circ} \mathrm{C}$ ). 

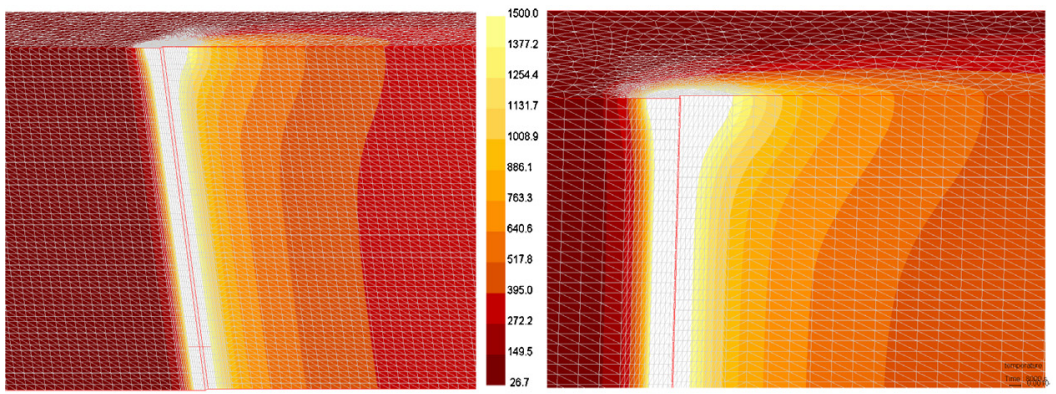

(a)

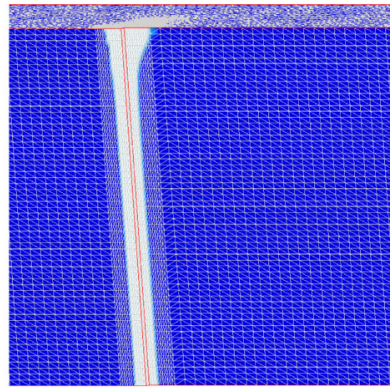

(b)

Fig. 11. (a) Detail around the melted zone (temperatures lower than $1500^{\circ} \mathrm{C}$ ) and (b) fusion zone (white is liquid metal, blue is solid metal).

induced stresses might reduce the performance of the whole steel construction after welding the flanges especially in term of fatigue and stability resistance (Fig. 11).

\section{Discussion}

An input power of $10^{11} \mathrm{~W} / \mathrm{m}^{3}$ is obtained in the present work. When multiplied by the volume used to define the heat source and reported in Eq. (2), this yields a power around $18.8 \mathrm{~kW}$. This value is within the range reported by O'Neill and Gabzdyl (2000) for laser-assisted oxygen cutting, i.e. powers ranging from 13 to $23 \mathrm{~kW}$ depending on plate thickness and cutting speed. For a cutting speed of $250 \mathrm{~mm} / \mathrm{min}$, i.e. $4.167 \mathrm{~mm} / \mathrm{s}$, the linear heat input amounts to $4.51 \mathrm{~kJ} / \mathrm{mm}$ in steady state. This value is much larger than the heat input around $0.4 \mathrm{~kJ} / \mathrm{mm}$ reported by Lindgren et al. (1983). It is thought that this difference comes from the fact that heat flow along the cutting direction was ignored by Lindgren et al. who used a 2D transverse model. However, Terasaki et al. (2009) obtained experimental results of heat input on the range of $3 \mathrm{~kJ} / \mathrm{mm}$ to $4 \mathrm{~kJ} / \mathrm{mm}$ for plate's thicknesses of $50.3 \mathrm{~mm}$ to $76.0 \mathrm{~mm}$. By averaging those values for a plate thickness of $60 \mathrm{~mm}$, the heat input is lower but comparable with the calibrated value of this study which is $4.51 \mathrm{~kJ} / \mathrm{mm}$.

Using the results presented above, the efficiency of the flame cutting process can be defined. Once the material is melted within the flame, it can be expelled downwards by the flow of gases. Using Eq. (3) with a mean liquid metal temperature of $2000^{\circ} \mathrm{C}$, the required power is $5 \mathrm{~kW}$, much less than $18.8 \mathrm{~kW}$ found in the present study. The ratio of these two powers yields a process efficiency of $26.5 \%$ in the steady state regime. In the transient initial piercing of the plate, higher input energies are expected.

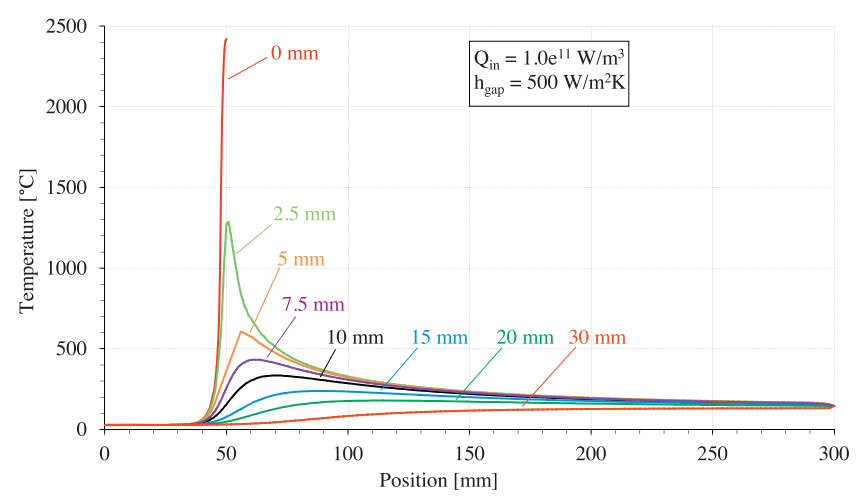

Fig. 12. Temperature profiles at different distances from the torch path.
The present thermal model is the first step toward better understanding the generation of thermally induced stresses during flame cutting, as these stresses are known to significantly impact the fatigue and stability behavior of welded structures.

\section{Conclusions}

- Flame cutting of $60 \mathrm{~mm}$ thick steel (S355N) flanges has been investigated using a steady state heat flow 3-D finite element model. With two parameters, (i) the heat density within the flame and (ii) the heat transfer coefficient within the air gap that forms behind the cut, the model is able to properly reproduce the temperature measurements, the fusion zone extensions, and the heat affected zone.

- The heat input power determined in the present work, $18.8 \mathrm{~kW}$, is similar to values reported in literature for thermal cutting of similar thicknesses.

- By considering the heat loss due to the leakage of molten steel, a process efficiency of $26.5 \%$ in the steady state regime is deduced.

\section{Acknowledgments}

The authors would like to thank Zwahlen \& Mayr (Aigle, Switzerland) for material provision. In addition, the authors would like to thank OFROU (Office fédéral des routes, Confédération Suisse) for supporting this research.

\section{References}

Adedayo, A.V., 2011. Kinetics of oxyfuel gas cutting of steels. Journal of the Brazilian Society of Mechanical Sciences and Engineering 33. $183-188$

CalcoSoft, 2005. FEM software distributed by Calcom ESI. www.calcom.ch

EN 10025-3, 2004. Hot rolled products of structural steels - Part 3: Technical delivery conditions for normalized/normalized rolled weldable fine grain structural steels. CEN, 2004.

Ermolaev, G., Kovalev, O.B., Zaitsev, A.V., 2013. Parameterization of hybrid laserassisted oxygen cutting of thick steel plates. Optics \& Laser Technology 47, 95-101

Lindgren, L.E., Carlestam, A., Jonsson, M., 1983. Computational model of flame-cutting. Journal of Engineering Materials and Technology 115, $440-445$

Lindgren, L.E., 2001. Finite element modeling and simulation of welding. Part 1: increased complexity. Journal of Thermal Stresses 24, 141-192.

McQuade, K., 2010. Plasma, oxyfuel and laser: matching metal cutting needs with the right cutting process. Welding and cutting 9, 91-94.

Mertens, A., 2012. Caractérisation thermophysique de deux échantillons d'acier. Université de Liège, Institut de Mécanique et de Génie Civil (B52), LTAS, Métallurgie et Science des Matériaux.

Muñoz-Escalona, P., Payares, M.C., Dorta, M., Diaz, R., 2006. Analysis and influence of acetylene and propane gas during oxyfuel gas cutting of 1045 carbon steel. Journal of materials engineering and performance 15, 684-692.

Osawa, N., Sawamura, J., Ikegami, M.Y., Okamoto, M.N., 2012. Study of Heat transfer during piercing process of oxyfuel gas cutting. Welding in the World 56, $2-10$. 
O'Neill, W., Gabzdyl, J., 2000. New developments in laser-assisted oxygen cutting. Optics and Lasers in Engineering 34, 355-367.

Rappaz, M., Desbiolles, J.-L., Drezet, J.-M., Gandin, Ch.-A., Jacot, A., Thévoz, Ph., 1995. Application of inverse methods to the estimation of boundary conditions and properties. Modeling of Casting, Welding and Advanced Solidification Processes, $449-457$.

Rosenthal, D., 1941. Mathematical theory of heat distribution during welding and cutting. Welding journal 20, 220-234.
Terasaki, T., Kitamura, T., Miyamoto, M., 2009. Heat input generated in plate by gas cutting process. Journal of the Japan Society of Naval Architects and Ocean Engineers 10, 197-204.

Thiébaud, R., Lebet, J.-P., 2012. Experimental study of residual stresses in thick stee plates. In: Structural Stability Research Council Annual Stability Conference, Grapevine, TX, USA 